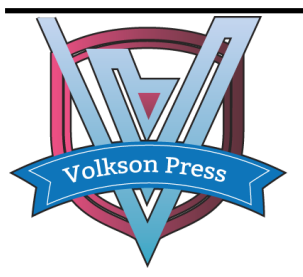

\title{
RESEARCH AND ANALYSIS OF ACADEMIC EXCHANGES AND COOPERATION BETWEEN CHINESE AND RUSSIAN COLLEGES AND UNIVERSITIES UNDER THE BACKGROUND OF "INTERNET +"
}

\author{
Teng Haikun*, Liu Xinsheng, Li Lunbin \\ Computer and Information Engineering College, Heihe University Academic Road No. 1, Heihe City, China. \\ *Corresponding Author Email: thk 1983@163.com
}

This is an open access article distributed under the Creative Commons Attribution License, which permits unrestricted use, distribution, and reproduction in any medium, provided the original work is properly cited

\section{ARTICLE DETAILS}

Article History:

Received 12 November 2017 Accepted 12 December 2017 Available online 1 January 2018

\begin{abstract}
through the analysis of the status quo of academic exchanges and cooperation between teachers and students in colleges and universities between China and Russia, is put forward based on the theory of "Internet + education", the idea using the network technology between teachers and students between China and Russia to build a pluralistic and open service platform for academic exchange between teachers and students in colleges and universities between China and Russia, change the traditional "face to face" or "a small number of elite" experience academic exchanges and cooperation, improve the quality of college teachers and students academic exchanges and cooperation between China and Russia, create a free academic atmosphere. The platform provides the omni-directional, various virtual network services, has carried on the powerful supplement to the traditional scientific communication mode, make up for the problem of unbalanced distribution of academic resources, to realize information resources sharing, academic exchanges and cooperation between teachers and students in colleges and universities between China and Russia to play an active role.
\end{abstract}

\section{KEYWORDS}

Chinese and Russian Universities and Teachers, Internet + Education, Academic Exchange, Virtual network Services

\section{INTRODUCTION}

The internationalization problem brought by economic globalization also manifests itself in the core area of the foundation -- education. The internationalization of education has become an irresistible trend, and international academic exchanges and cooperation have become the main way to realize the internationalization of education [1]. "Much starker choices-and graver consequences-in" period with the help of the two countries "corridor" in the Russian economy development opportunities, and actively seek education field of cooperation between colleges and universities between China and Russia, and natural geographical neighbors of the two countries, the good tradition of cooperation, all the way for the exchanges and cooperation of colleges and universities are of great opportunity.

With the advent of the era of "Internet +", information exchange has become more open, and exchanges and cooperation between China and Russia have been fully developed. In addition to the opportunity, we should face the problem directly [2]. To this end, we faced with opportunities to meet the challenge, to exchange and cooperation between the two countries universities have the scale and characteristics, and with the aid of this advantage platform, to create a high level in our country and the world first-class university of success and the steady step on the road.

Academic exchange and cooperation is an important part of the work of institutions of higher learning, is an omni-directional, multilevel and society's exchange and the cooperation of media, is to facilitate and promote the academic prosperity and development of the indispensable conditions and component, as well as teaching set up various kinds of communication platform, enrich the teaching content, improve the quality of teaching and cultivating innovative talents, effectively promote the development of the teaching work [3]. In conclusion, academic exchanges and cooperation can not only promote the normal operation and sustainable development of scientific research, but also contribute to the completion of three major tasks of teaching, scientific research and service.

\section{PROBLEMS AND SOLUTIONS OF ACADEMIC EXCHANGES AND COOPERATION BETWEEN CHINESE AND RUSSIAN UNIVERSITIES UNDER THE "INTERNET+ BACKGROUND"}

As is known to all, Russia has a long history and culture of education developed science and education country, there are more than 1,000 universities, some of which are renowned on the world stage [4]. Heilongjiang province as the bridgehead of international exchanges and cooperation between China and Russia, have a large number of institutions of higher learning, if you want to improve their own comprehensive strength, want to share the international stage "education internationalization", will have considerable academic atmosphere, and create a strong academic atmosphere is extensive academic exchanges.

However, academic exchanges and cooperation with Russian universities are traditional communication methods: holding academic conferences; Academic reports and lectures; Science investigation; Exchange of scientific and technological information and special journals; Personal interactions among experts and scholars [5]. Although these communication methods can play a positive role, but restricted by language, geography, participation and so on makes the effectiveness of the role of academic communication is difficult to play enough, more than a propaganda role on a nationwide scale.

With the development of network information technology, more and more academic exchanges advocated under the environment of information, no longer limited by number, language, and region, the rich academic 
resources, convenient interaction, timeliness of information greatly changed the way people's academic exchanges, make the future of academic communication coruscate gives new vitality. At the third session of the 12th National People's Congress, Premier Li keqiang proposed the "Internet +" action plan to elevate the "Internet +" to the national strategic level. On June 14, 2015 at the 2015 China Internet + innovation summit in Hebei, the authority of the industry experts and scholars around the central issue, "Internet + education" by having their own point of view, the state attaches great importance to.

Based on the "Internet + education" as the theoretical basis, assumptions on the network and between teachers and students between China and Russia to build a pluralistic, open service platform for academic exchange between teachers and students in colleges and universities between China and Russia, change the traditional "face to face" or "a small number of elite" experience academic exchanges and competition way, provides the academic exchanges between teachers and students in colleges and universities between China and Russia is more convenient, open communication, a strong complement to the traditional scientific communication mode, make up for the problem of unbalanced distribution of academic resources, to realize information resources sharing, the bilateral combination of "production". The architecture of the academic exchange platform of Chinese and Russian colleges and universities based on Internet information technology is shown in figure 1.

\section{THE POSITIVE ROLE OF CHINA-RUSSIA ACADEMIC EXCHANGE AND COOPERATION PLATFORM}

Online academic communication has brought a new performance style and pattern, provides the academic exchanges between teachers and students in colleges and universities between China and Russia is more convenient, open communication, a strong complement to the traditional scientific communication mode, greatly satisfy the scientific research and teaching staff under the network environment, the demand of the international academic communication and knowledge sharing, and gradually become a new trend of the exchange of academic research [6]. The Sino-Russian academic exchange and cooperation platform explored in this paper should have the following functions:

(1) Based on the existing university academic exchanges between China and Russia form and content of research and analysis, put forward in "Internet +" form, using Internet technology to build college academic exchange platform between China and Russia, change the traditional "face to face" or "a small number of elite" experience of academic communication, create an information resource sharing platform, seeking more opportunity for academic exchanges between colleges and universities between China and Russia.

(2) Academic exchanges are closed by the past few people and gradually move towards the openness of most people. The atmosphere of academic research will also be very lively, making the academic style more interesting and enlightening. If academic research can take this approach more, the effect must be optimal.

(3) Promote the popularization of academic exchanges. With special geographic position of traditional academic exchange opportunities is more, but their results show or publicity materials only update in our website, and will not cause the attention of other university academic personnel. And this topic proposed platform is open to all interested in academic exchanges between China and Russia, college teachers and students can, to some extent compensate for the uneven distribution of resources, make the students or teachers that do not directly participate in academic exchanges for related information and knowledge, can also directly through the platform timely exchange of experience with participants, enlightenment thoughts, enhance creative thinking. It improves the enthusiasm of teachers and students and reduces the expenditure of academic exchange.

(4) Academic exchange platform for the university academic culture between China and Russia have propaganda effect, for the two peoples to understand both culture expands out a very important way, the two peoples in the medium of education exchanges and cooperation, further understanding of each other's culture, history, local conditions and customs, etc., and deepen the friendship between the two peoples.

Academic exchange platform between teachers and students in colleges and universities between China and Russia as learning, communication and interaction between teachers and students between China and Russia is a body comprehensive platform, must focus on the simulation of daily academic communication environment, teachers and students in colleges and universities to provide a full range, many aspects of the virtual network services [7]. This paper discusses the existing problems and countermeasures of the academic exchanges between Chinese and Russian colleges and universities in the context of "Internet +", and plays an active role in the academic exchanges and cooperation between Chinese and Russian colleges and universities [8].

\section{CONCLUSION}

Based on the analysis of the problems existing in the academic exchanges and cooperation between teachers and students in colleges and universities between China and Russia on the basis, combining with the characteristics of the current Chinese higher education management model and offered to "Internet +" as the background, advocating academic exchanges and cooperation under the environment of information, ideas to build a multi-level role management mode of academic exchanges and cooperation platform, promote academic exchange and cooperation in the formation of a new way to make academic exchanges and cooperation between teachers and students in colleges and universities between China and Russia is no longer restricted by factors such as time, place, and language, arouse the enthusiasm of teachers and students in colleges and universities between China and Russia, to achieve resource sharing and convenient way of interaction. Diversified academic exchanges can ensure the effectiveness and quality of academic exchanges and cooperation, enlighten ideas, enhance creative thinking, and promote all-round cooperation between Chinese and Russian universities

\section{ACKNOWLEDGEMENT}

This paper is supported by Hei Long Jiang Education Science "13th fiveyear plan" 2017 Annual Record Project--Provincial Youth Special Project: Research and Practice of Academic Exchange Model between Chinese and Russian Colleges and Universities under the Background of "Internet+"(GBD1317062).

\section{REFERENCES}

[1] Hongjiang, J., Shaohua, X., Ying, W. 2017. Research on education international communication and cooperation under the strategy of "one belt and one road" [J]. Journal of Kunming university of science and technology (social science edition), (01).

[2] Zheng, Y., Jianqiu, L. 2018. The problems, countermeasures and Suggestions of academic exchanges in universities [J]. Scientific management research, (03)

[3] Gang, Z., Jinsheng, L. 2016. The dilemma and countermeasures of education communication and cooperation in One Belt and One Road strategy [J]. Comparison of education research,

[4] Kai, C. 2008. Research on the form, organizational strategy and innovative practice of academic exchanges in universities [J]. Journal of Xihua University (philosophy and social science edition), (02)

[5] Xinrong, L. 2010. Research on the differences between academic exchange and traditional academic exchanges based on the platform of "institutional collection" [J]. (07)

[6] Changying, W. 2009. Research on international exchange and cooperation between Chinese and Russian universities [J]. (04)

[7] Xudong, Z. 2012. Academic communication system based on social network [D]. Dalian: Dalian university of technology,

[8] Wen, S. 2013. Research on the building of community platform of interactive researchers based on Web2.0 [D]. Xiangtan University. 